\title{
Prevalence of Class 1 Integron and Antibiotic Resistance Pattern in Pseudomonas aeruginosa Isolated from Iranian Clinical Specimens; a Systematic Review and Meta- Analysis
}

\section{Elham Zarifi}

Shahid Sadoughi Yazd Uni Med Sci

Yasamin Enayati Kaliji

Azad Uni Med Sci

Azad Khaledi ( $\sim$ azadkh99@gmail.com )

Antimicrobial Research Center, Avicenna Research Center, Department of Microbiology and Virology, Facaulty of Medicine, Mashhad University Medical Sciences, Mashhad

Mohammadreza Rahimi

Kashan Uni Med Sci

Mahtab Babadi

Kashan Uni Med Sci

\section{Research article}

Keywords: Antibiotic resistance, Clinical specimens, Integron, Iran, Pseudomonas aeruginosa

Posted Date: May 21st, 2019

DOI: https://doi.org/10.21203/rs.2.9715/v1

License: (c) (i) This work is licensed under a Creative Commons Attribution 4.0 International License. Read Full License 


\section{Abstract}

Background The role of integrons has been shown in the horizontal transmission of antibiotic resistance genes among bacterial isolates especially Gram-negative microorganisms in clinical settings. Objectives The aim of this study was to systematically review the prevalence of class 1 integrons and antibiotic resistance in Pseudomonas aeruginosa isolates of clinical samples of Iranian patients. Methods The Web of Science, PubMed, Scopus, and Science Direct databases were searched using preferred keywords based on the Preferred Reporting Items for Systematic Review and Meta-Analyses (PRISMA) guidelines. The cross-sectional studies addressing the frequency of class 1 integrons and antibiotic-resistance in P. aeruginosa isolates from clinical samples of Iranian patients published from 1 January 2000 until 31 December 2018 were included. Meta-analysis was performed using Comprehensive Meta-Analysis $\neg$ (CMA) software. The random effects model was used for meta-analysis. The Cochran's Q and 12 tests were applied for statistical analyses. Publication bias was assessed using Funnel plot and Egger's linear regression test. Results Out of 911 studies retrieved in the initial search, 17 articles met the eligibility standards for being included in the meta-analysis. The Egger's linear regression test indicated no publication bias $(P=$ 0.95). The combined prevalence of class 1 integrons in P. aeruginosa isolates was obtained as 58.9\% (95\% Cl: 46.3$70.4 \%$ ). The highest rate of combined antibiotic resistance was related to Carbenicillin with a resistance rate of $79.9 \%$. On the other side, the most effective antibiotic against P. aeruginosa was Polymyxin B with the resistance rate of $0 \%$. The pooled prevalence of multi-drug resistant (MDR) P. aeruginosa isolates was 55\% ( $\neg 95 \% \mathrm{Cl}$ : 33.8-75.3\%). Conclusions Our findings indicated the high prevalence of class 1 integrons and antibiotic resistance among P. aeruginosa isolates of Iranian patients' clinical samples. Also, the prevalence of MDR P. aeruginosa isolates was noticeable requiring prompt action.

\section{Background}

Pseudomonas aeruginosa is a non-fermentative aerobic Gram-negative bacillus and a common nosocomial pathogen. $P$. aeruginosa is one of the dreadful causes of severe infections in clinical settings particularly in immunecompromised patients, as well as individuals hospitalized in Intensive Care Unit (ICU), patients with cystic fibrosis, and those with severe burns [1]. Although the antibiotics are the main therapeutics to control the infections caused by this microorganism, the inherent resistance of $P$. aeruginosa to antibiotics is increasing [2].

The selective pressure of inappropriate antibiotic consumers on one hand, and the increasing use of antibiotics on the other hand are probably the main causes for the development of multidrug-resistant (MDR) P. aeruginosa in hospital settings [3]. MDR P. aeruginosa isolates are those showing resistant against three classes of conventional antibiotics particularly aminoglycosides, carbapenems, and fluoroquinolones [4].

Infections caused by MDR-Pseudomonas aeruginosa strainspresent clinically significant challenges. The empirical antibiotic therapy for MDR P. aeruginosa has represented poor outcomes with high morbidities, mortalities, long hospital stays and high economic and therapeutic burden on both health systems and the patients [5].

According to the reports of the European Centre for Disease Prevention and Control(CDC), P. aeruginosa comprises $9 \%$ of all hospital-based infections presenting the fourth most common hospital pathogen in Europe [ 6]. Also, CDC reported similar findings in the United States with the frequency of about $7 \%$ for $P$. aeruginosa infections in hospital settings [ 7]. A survey in Spain in 2016 reported a higher prevalence about 13\% for this microorganism in ICU units of hospitals [ 8]. In European countries, the prevalence of MDR P. aeruginosa isolates was reported nearly 30\% [ 9]. The rate of MDR P. aeruginosa isolates in Iran; however, has been reported between $30-100 \%$ [ 10]. 
Some possible antimicrobial resistance mechanisms in $P$. aeruginosa include the production of beta-lactamases, overexpression of efflux pumps, down regulation of outer membrane porins, production of AmpC or loss of OprD, genetic mutations, and finally expression of integrons on plasmids and transposons [6, 11]. The integrons are specialized genetic structures by which bacteria can acquire resistance genes through horizontal transmission [ 12].

Integrons can acquire external drug resistance gene cassettes and integrate them by site-specific recombination. In clinical settings, integrons facilitate rapid horizontal transmission of antibiotic resistance genes among bacterial isolates especially Gram-negative microorganisms [ 13,14]. Generally, integrons comprise of an integrase gene, two conserved sequences called sul 1 and int1, and a variable region harboring gene cassettes between the two conserved fragments [15].

Based on the structure of integrase gene, several classes of integrons have been recognized. Three main classes of integrons (i.e. class 1, 2, and 3) have been identified in Gram-negative bacteria including Enterobacteriaceae, and Pseudomonas. Among these, class 1 integrons are the most frequent in these microorganisms. Class 1 integrons usually carry one or several gene cassettes conferring resistance to a broad spectrum of antibacterial agents such as $\beta$-lactams, aminoglycosides and fluoroquinolones [16, 17].

It is necessary to comprehend the prevalence of MDR $P$. aeruginosa and the mechanisms associated with antibiotic resistance (such as the presence of integrons) to eradicate infections caused by this organism. Regarding the significance of $P$. aeruginosa in hospital acquired infections, and the lack of a comprehensive study on the prevalence of class 1 integrons in $P$. aeruginosa isolates and antimicrobial resistance patterns of this organism in Iran, we aimed to investigate the prevalence of class 1 integrons and antibiotic resistance patterns of $P$. aeruginosa recovered from clinical samples of Iranian patients.

\section{Results}

A total of 911 relevant articles were obtained in the primary literature search (Figure 1). Out of these, 456 duplicate studies were excluded. Also, 90 records with irrelevant titles were deleted. After reading the abstracts of 365 remained papers, 259 were excluded owing to justified reasons. Then, 106 full text studies assessed. From these, 89 studies were omitted due to either lack of data accessibility, missing data, or not reporting the frequency of class 1 integrons. Finally, 17 articles were included in the meta-analysis (Figure 1).

The combined prevalence of class 1 integrons in $P$. aeruginosa isolated from clinical specimens of Iranian patients varied from $13.3 \%$ to $99.1 \%$ (Figure 2). The clinical samples were mostly collected from ICU and Burn units. The pooled prevalence of MDR $P$. aeruginosa isolates varied from 13.1 to $100 \%$. Overall, 11 out of the 17 included studies (64.7\%) described a correlation between the presence of class 1 integrons and antibiotic resistance (Table 1, $P$ value < $0.05)$.

\section{Overall effects}

There was a statistically significant heterogeneity among the included studies $\left(\mathrm{Q} 2=341.7, \mathrm{I}^{2}=95.3, \mathrm{t}=1.2, P=0.00\right)$. Accordingly, the random effects model was applied to combine the prevalence of class 1 integrons in $P$. aeruginosa isolates. The combined prevalence of class 1 integrons was obtained as 58.9\% (95\% Cl: 46.3-70.4\%) in Iranian patients' clinical specimens (Table 2). The publication bias was checked using Funnel plot. Concerning possible asymmetrical data distribution in the selected studies, the Egger's linear regression test was used to further evaluate any publication bias. Nevertheless, the results of the Egger's linear regression test revealed no publication bias 
$(P=0.95)$. The pooled prevalence of MDR $P$. aeruginosa isolates was obtained as $55 \%(95 \% \mathrm{Cl}: 33.8-75.3 \%)$. Subgroups analysis revealed that the highest combined antibiotic resistance belonged to Carbenicillin following by Cloxacillin and Cefotaxime with respective resistance rates of $79.9 \%, 77.4 \%$, and $76.6 \%$. On the other hand, the most effective antibiotics against $P$. aeruginosa were Polymyxin B and Colistin each with resistance rate of $0 \%$ (Table 3 ).

\section{Discussion}

The non-lactose fermentative Gram-negative pathogens, especially $P$. aeruginosa, are emerging causes of nosocomial infections in patients hospitalized in ICU and Burn units [19].

In the present study, the combined prevalence of class 1 integrons in $P$. aeruginosa isolates was obtained as $58.9 \%$ ranging from $13.3 \%$ to $99.1 \%$. About $64.7 \%$ of the included studies described a correlation between the presence of class 1 integrons and antibiotic resistance among $P$. aeruginosa isolates.

The noticeable differences and variability in the distribution of class 1 integrons among the Iranian studies included in the current systematic review may be partly due to the heterogeneities in the patterns of antibiotics usage, as well as the sources of infections and geographical locations [20]. Integrons carrying gene cassettes provide a powerful vehicle for the fast horizontal transmission of antibiotic resistance genes among different bacterial populations, and in this manner, contribute to the dissemination of antibiotic resistance in hospital settings which delivers a serious concern for human health services [12]. Similar to our findings, several researchers such as Ren et al. (2012) in the United States [21], Cholley et al. (2011) in France[ 22], and Taccone et al. (2012) in Brooklyn [23] have reported an association between the expression of class 1 integrons and antibiotic resistance in bacterial strains. In accordance with our findings, the class 1 integrons have been reported as the most common integrons expressed in $P$. aeruginosa isolates in studies conducted in Japan [24], Spain [12], and China[ 13].

The high frequency of integrons; particularly class 1 integrons, among resistant $P$. aeruginosa isolates highlights a role for these genetic elements in resistance to antimicrobial agents. We here encountered relatively high rates of resistant $P$. aeruginosa inthe ICU and burn units of hospitals, patients in these units are particularly susceptible to infections by MDR $P$. aeruginosa. Inappropriate empirical antibiotic therapy in infections caused by MDR $P$. aeruginosa strainshas resulted in increased mortality, prolonged hospitalization and elevated hospital costs [7]. Thus, particular strategies should be implemented to prevent the colonization of Gram-negative bacteria such as $P$. aeruginosa and transmission of resistance genes among these microorganisms through integrons in hospital settings [ 25].

Nevertheless, some included studies showed no relationship between the presence of integrons and antibiotic resistance in $P$. aeruginosa. This may partially be related to the contribution of other mechanisms involved in antibiotic resistance such as the overexpression of $\mathrm{AmpC}$ beta lactamase (which is encoded by chromosomal genome), the repression or inactivation of Carbapenem porin OprD, and the up-regulation of different efflux pumps [ 6].

In the present review, the pooled prevalence of MDR P. aeruginosa isolates recovered from clinical specimens of Iranian patients was 55\%. In comparison, the frequency of MDR P. aeruginosa isolateswas reported $30 \%$ in eastern European countries [ 9] that was lower than the ratio obtained here. In line with our findings; however, other studies in China [26], and Brazil [27] reported the high frequency of MDR P. aeruginosa isolates. In accordance with our results, Fonseca et al. showed that more than half of Imipenem-resistant and almost all MDR $P$. aeruginosa isolates expressed class 1 integrons [27].

In the current study, the most effective antibiotics against $P$. aeruginosa isolates were Polymyxin B and Colistin each with susceptibility rate of $100 \%$. This is while most of $P$. aeruginosa isolates represented the high resistance toward 
Carbenicillin (79.9\%), Cloxacillin (77.4\%), and Cefotaxime (76.6\%). Polymyxin B and colistin are among the most important anti-pseudomonal antibiotics with the highest effects against MDR P. aeruginosa isolates. However, both of these antibiotics have been associated with side effects and toxicities [ 6]. In fact, the restricted prescription of Polymyxins because of their toxicity is probably the most important reason for the high susceptibility rate (100\%) of $P$. aeruginosa isolatesin exposure to these antibiotics [28]. Accordingly, a report from Spain in 2015 revealed a high rate of combined resistance to three or more frequently prescribed antimicrobial agents (piperacillin-tazobactam, Ceftazidime, fluoroquinolones, aminoglycosides and Carbapenems) among P. aeruginosa isolates[29]. As well, polymyxins have shown the highest antibacterial activity among XDR P. aeruginosa isolates [ 9] which is in agreement with our results.

To the best of our knowledge, fluoroquinolones (such as Ciprofloxacin) are among the most effective available antibiotics for the treatment of P.aeruginosa infections, particularly urinary tract infections [ 30]. In this study; however, more than $50 \%$ of $P$. aeruginosa isolates showed resistance against Ciprofloxacin. According to the studies conducted in Latin America and Europe, 25-30\% of $P$. aeruginosa isolates were also resistant to Ciprofloxacin [ 31, 32]. In addition, we encountered a broad resistance rate against beta-lactams and aminoglycosides in $P$. aeruginosa strainswhich is in line with the results of previous studies [26,33]. On the contrary, others have described low resistance rates of $P$. aeruginosa against aminoglycosides $[25,27]$.

It is noteworthy that hospital acquired infections caused by MDR bacterial isolates are relatively frequent in developing countries such as Iran in comparison with developed nations such as the USA and most European countries. This difference can be explained by the effective programs implemented to prevent and control nosocomial hospital infections in developed countries [34]. This is while the hospital-based committees for controlling infections are either unavailable or their members are inexperienced and untrained in developing countries. Therefore, it is advisable to recruit clinical microbiologists for effective management of nosocomial infections in hospitals [ 35, 36].

Overall, the prevalence of MDR P. aeruginosa isolates was high in clinical samples obtained from Iranian patients especially those hospitalized in critical care units (i.e. ICU and Burn). Furthermore, a high penetrance of class 1 integrons was noted in the MDR P. aeruginosa isolates delineating their association with antibiotic resistance in these bacteria. Timely reporting of antibiotic resistance patterns in these bacteria is recommended to prescribe appropriate antibiotics. Also, it is recommended to develop hospital-based infection control committees and educate their members regarding the nosocomial infections control programs.

In this review, we included only the articles published in English which is a limitation of our study. Also, we did not include unpublished literatures in the present review.

\section{Conclusions}

Our findings indicated the high prevalence of class 1 integrons and antibiotic resistance among $P$. aeruginosa isolates of Iranian patients' clinical samples. Also, the prevalence of MDR $P$. aeruginosa isolates was noticeable requiring prompt action.

\section{Materials And Methods Search strategy}

The studies addressing the prevalence of class 1 integrons and antibiotic resistance pattern of $P$. aeruginosa isolatesfrom Iranian patients' clinical specimens published from January 2000 to the end of 2018 were included. The 
search was carried out in Web of Science, Cochrane Library, Scopus, PubMed, and Google Scholar databases. The search was restricted to the English original articles reporting either the prevalence or incidence of $P$. aeruginosa. The following keywords from Medical Subject Headings or titles or abstracts were used with the help of Boolean operators (and, or): $P$. aeruginosa, burned patients, drug susceptibility, and drug resistance. The keywords of Integrons, Pseudomonas aeruginosa or $P$. aeruginosa, prevalence/incidence and distribution of INT1 in Pseudomonas aeruginosa, Iran, Int1, antibiotic resistance, and local studies were used alone or in combination to conduct a complete search antibiotic resistance.

\section{Inclusion and exclusion criteria}

All the original articles reporting the prevalence, incidence and distribution of integrons in $P$. aeruginosa isolated from Iranian patients' clinical specimens were included. Only those studies that performed antibiotic susceptibility test based on CLSI guidelines were considered. Foreign studies (i.e. not performed in Iran) and those studies that did not follow CLSI directions in performing antibiotic susceptibility test were excluded. Also, narrative and systematic reviews, meta-analyses, editorials, prospective studies, congress abstracts, case reports, and letters to the editors were omitted. Studies published in languages other than English, articles only available in abstract form and also duplicate publications were excluded.

\section{Data extraction}

The intended data including first author's name, year of publication, location of study, sample size, the frequencies of MDR and class 1 integrons, hospital wards, and correlation between the presence of integrons and antibiotic resistance were recorded in a data extraction form designed by the researchers.

\section{Qualification of the studies}

The strengthening the reporting of observational studies in epidemiology (STROBE) checklist was utilized for qualifying the methodology of the included studies [18]. Based on the qualification criteria, the studies were categorized as high, medium or low quality.

\section{Statistical analysis}

The data was analyzed using Comprehensive Meta-Analysis software (Version 3.3.070). The prevalence of class 1 integrons in $P$. aeruginosa isolated from Iranian patients' clinical samples was reported with $95 \%$ confidence interval $(\mathrm{Cl})$. The random effects model was used for meta-analysis. The statistical heterogeneity among the studies was determined by Cochrane $Q$ and $R$ tests. To evaluate possible publication bias, the funnel plot and quantitative Egger weighted regression test were applied. $P$ value $<0.05$ was considered as the statistical significance cut off for detecting any publication bias.

\section{Abbreviations}

PRISMA: Preferred Reporting Items for Systematic Review and Meta-Analyses, CMA: Comprehensive Meta-Analysis, MDR: multi-drug resistant, ICU: Intensive Care Unit, CDC: Centre for Disease Prevention and Control, STROBE: Strengthening the reporting of observational studies in epidemiology, Cl: Confidence interval. 


\section{Declarations}

\section{Acknowledgments}

We would like to thank our colleagues for their help in this present study.

\section{Funding}

This study did not receive any financial support.

\section{Availability of data and materials}

The data can be accessible to the interested researchers by the corresponding authors on reasonable request.

\section{Authors' contributions}

EZ and designed the study. YEK and AK contributed in the searching process, and drafting the work. MR and MB performed the analysis of the data. All authors read and approved the final manuscript.

\section{Ethics approval and consent to participate}

Not applicable.

\section{Consent for publication}

Not applicable.

\section{Competing interests}

The authors declare that they have no competing interests.

\section{References}

1. Sadikot RT, Blackwell TS, Christman JW, Prince AS. Pathogen-host interactions in Pseudomonas aeruginosa pneumonia. American journal of respiratory and critical care medicine. 2005;171(11):1209-23.

2. Hosseini SMJ, Naeini NS, Khaledi A, Daymad SF, Esmaeili D. Evaluate the Relationship Between Class 1 Integrons and Drug Resistance Genes in Clinical Isolates of Pseudomonas aeruginosa. The open microbiology journal. 2016;10:188.

3. Mobaraki S, Aghazadeh M, Barhaghi MHS, Memar MY, Goli HR, Gholizadeh P, et al. Prevalence of integrons 1, 2, 3 associated with antibiotic resistance in Pseudomonas aeruginosa isolates from Northwest of Iran. BioMedicine. 2018;8(1).

4. Rossolini G, Mantengoli E. Treatment and control of severe infections caused by multiresistant Pseudomonas aeruginosa. Clinical Microbiology and Infection. 2005;11:17-32.

5. Haidar G, Philips NJ, Shields RK, Snyder D, Cheng S, Potoski BA, et al. Ceftolozane-tazobactam for the treatment of multidrug-resistant Pseudomonas aeruginosa infections: clinical effectiveness and evolution of resistance. Clinical Infectious Diseases. 2017;65(1):110-20.

6. Ruiz-Garbajosa P, Canton R. Epidemiology of antibiotic resistance in Pseudomonas aeruginosa. Implications for empiric and definitive therapy. Revista Española de Quimioterapia. 2017;30. 
7. Magill SS, Edwards JR, Bamberg W, Beldavs ZG, Dumyati G, Kainer MA, et al. Multistate point-prevalence survey of health care-associated infections. New England Journal of Medicine. 2014;370(13):1198-208.

8. Palomar M, Álvarez-Lerma F, Olaechea P, Insausti J, López-Pueyo M. Estudio nacional de vigilancia de infección nosocomial en servicios de medicina intensiva. SEMICYUC[Consultado el 10 dic 2014] Disponible en: URL: http://hwsvhebron net/envin-helics/Help/Informe\% 20ENVIN-UCI. 2008;202012.

9. Oliver A, Mulet X, Lopez-Causape C, Juan C. The increasing threat of Pseudomonas aeruginosa high-risk clones. Drug Resistance Updates. 2015;21:41-59.

10. Vaez H, Salehi-Abargouei A, Ghalehnoo ZR, Khademi F. Multidrug resistant Pseudomonas aeruginosa in Iran: A systematic review and metaanalysis. Journal of global infectious diseases. 2018;10(4):212.

11. Carattoli A. Importance of integrons in the diffusion of resistance. Veterinary research. 2001;32(3-4):243-59.

12. Ruiz-Martínez L, López-Jiménez L, Fusté E, Vinuesa T, Martínez J, Viñas M. Class 1 integrons in environmental and clinical isolates of Pseudomonas aeruginosa. International journal of antimicrobial agents. 2011;38(5):398-402.

13. Gu B, Tong M, Zhao W, Liu G, Ning M, Pan S, et al. Prevalence and characterization of class I integrons among Pseudomonas aeruginosa and Acinetobacter baumannii isolates from patients in Nanjing, China. Journal of clinical microbiology. 2007;45(1):241-3.

14. Mazel D, Dychinco B, Webb VA, Davies J. Antibiotic resistance in the ECOR collection: integrons and identification of a novel aad gene. Antimicrobial Agents and Chemotherapy. 2000;44(6):1568-74.

15. Gillings MR, Gaze WH, Pruden A, Smalla K, Tiedje JM, Zhu Y-G. Using the class 1 integron-integrase gene as a proxy for anthropogenic pollution. The ISME journal. 2015;9(6):1269.

16. Deng Y, Bao X, Ji L, Chen L, Liu J, Miao J, et al. Resistance integrons: class 1, 2 and 3 integrons. Annals of clinical microbiology and antimicrobials. 2015;14(1):45.

17. Hall RM, Collis CM. Antibiotic resistance in gram-negative bacteria: the role of gene cassettes and integrons. Drug resistance UPDATES. 1998;1(2):109-19.

18. Vandenbroucke JP, Von Elm E, Altman DG, Gøtzsche PC, Mulrow CD, Pocock SJ, et al. Strengthening the Reporting of Observational Studies in Epidemiology (STROBE): explanation and elaboration. Annals of internal medicine. 2007;147(8):W-163-W-94.

19. Phu VD, Wertheim HF, Larsson M, Nadjm B, Dinh Q-D, Nilsson LE, et al. Burden of hospital acquired infections and antimicrobial use in Vietnamese adult intensive care units. PloS one. 2016;11(1):e0147544.

20. Faghri J, Nouri S, Jalalifar S, Zalipoor M, Halaji M. Investigation of antimicrobial susceptibility, class I and II integrons among Pseudomonas aeruginosa isolates from hospitalized patients in Isfahan, Iran. BMC research notes. 2018;11(1):806.

21. Ren CL, Konstan MW, Yegin A, Rasouliyan L, Trzaskoma B, Morgan WJ, et al. Multiple antibiotic-resistant Pseudomonas aeruginosa and lung function decline in patients with cystic fibrosis. Journal of Cystic Fibrosis. 2012;11(4):293-9. 
22. Cholley P, Thouverez M, Hocquet D, Van Der Mee-Marquet N, Talon D, Bertrand X. Most multidrug-resistant Pseudomonas aeruginosa isolates from hospitals in eastern France belong to a few clonal types. Journal of clinical microbiology. 2011;49(7):2578-83.

23. Taccone FS, Cotton F, Roisin S, Vincent J-L, Jacobs F. Optimal meropenem concentrations to treat multidrugresistant Pseudomonas aeruginosa septic shock. Antimicrobial agents and chemotherapy. 2012;56(4):2129-31.

24. Shibata N, Doi Y, Yamane K, Yagi T, Kurokawa H, Shibayama K, et al. PCR typing of genetic determinants for metallo- $\beta$-lactamases and integrases carried by gram-negative bacteria isolated in Japan, with focus on the class 3 integron. Journal of Clinical Microbiology. 2003;41(12):5407-13.

25. Shahandashti EF, Molana Z, Asgharpour F, Mojtahedi A, Rajabnia R. Molecular detection of Integron genes and pattern of antibiotic resistance in Pseudomonas aeruginosa strains isolated from intensive care unit, Shahid Beheshti Hospital, North of Iran. International journal of molecular and cellular medicine. 2012;1(4):209.

26. Chen J, Su Z, Liu Y, Wang S, Dai X, Li Y, et al. Identification and characterization of class 1 integrons among Pseudomonas aeruginosa isolates from patients in Zhenjiang, China. International Journal of Infectious Diseases. 2009;13(6):717-21.

27. Fonseca ÉL, Vieira VV, Cipriano R, Vicente AC. Class 1 integrons in Pseudomonas aeruginosa isolates from clinical settings in Amazon region, Brazil. FEMS Immunology \& Medical Microbiology. 2005;44(3):303-9.

28. Fernández L, Álvarez-Ortega C, Wiegand I, Olivares J, Kocíncová D, Lam JS, et al. Characterization of the polymyxin $B$ resistome of Pseudomonas aeruginosa. Antimicrobial agents and chemotherapy. 2013;57(1):110-9.

29. Gelband H, Molly Miller P, Pant S, Gandra S, Levinson J, Barter D, et al. The state of the world's antibiotics 2015. Wound Healing Southern Africa. 2015;8(2):30-4.

30. Gales A, Jones R, Turnidge J, Rennie R, Ramphal R. Characterization of Pseudomonas aeruginosa isolates: occurrence rates, antimicrobial susceptibility patterns, and molecular typing in the global SENTRY Antimicrobial Surveillance Program, 1997-1999. Clinical Infectious Diseases. 2001;32(Supplement_2):S146-S55.

31. Brown PD, Izundu A. Antibiotic resistance in clinical isolates of Pseudomonas aeruginosa in Jamaica. Revista Panamericana de Salud Pública. 2004;16:125-30.

32. Bouza E, Garcia-Garrote F, Cercenado E, Marin M, Diaz M. Pseudomonas aeruginosa: a survey of resistance in 136 hospitals in Spain. Antimicrobial Agents and chemotherapy. 1999;43(4):981-2.

33. Poonsuk K, Tribuddharat C, Chuanchuen R. Class 1 integrons in Pseudomonas aeruginosa and Acinetobacter baumannii isolated from clinical isolates. Southeast Asian Journal of Tropical Medicine and Public Health. 2012;43(2):376.

34. Zhang S, Sun X, Chang W, Dai Y, Ma X. Systematic review and meta-analysis of the epidemiology of vancomycinintermediate and heterogeneous vancomycin-intermediate Staphylococcus aureus isolates. PloS one. 2015;10(8):e0136082.

35. Jabalameli F, Taki E, Emaneini M, Beigverdi R. Prevalence of metallo- $\beta$-lactamase-encoding genes among carbapenem-resistant Pseudomonas aeruginosa strains isolated from burn patients in Iran. Revista da Sociedade Brasileira de Medicina Tropical. 2018;51(3):270-6. 
36. Ider B-E, Adams J, Morton A, Whitby M, Clements A. Perceptions of healthcare professionals regarding the main challenges and barriers to effective hospital infection control in Mongolia: a qualitative study. BMC infectious diseases. 2012;12(1):170.

37. Yousefi S, Nahaei M, Farajnia S, Ghojazadeh M, Akhi M, Sharifi Y, et al. Class 1 integron and imipenem resistance in clinical isolates of Pseudomonas aeruginosa: prevalence and antibiotic susceptibility. Iranian journal of microbiology. 2010;2(3):115.

38. Nikokar I, Tishayar A, Flakiyan Z, Alijani K, Rehana-Banisaeed S, Hossinpour M, et al. Antibiotic resistance and frequency of class 1 integrons among Pseudomonas aeruginosa, isolated from burn patients in Guilan, Iran. Iranian journal of microbiology. 2013;5(1):36.

39. GOUDARZI SM, Eftekhar F. Multidrug resistance and integron carriage in clinical isolates ofPseudomonas aeruginosa in Tehran, Iran. Turkish journal of medical sciences. 2015;45(4):789-93.

40. Goudarzi M, Fazeli M, Azad M, Seyedjavadi S, Mousavi R, Rashidan M, et al. Carriage of Class 1 and Class 2 Integron in Multidrug Resistant Pseudomonas aeruginosa Isolated from Burn Patients in Tehran Hospitals, Iran. West Indian Medical Journal. 2016;65(1).

41. Aryanezhad M, Shakibaie MR, Karmostaji A, Shakibaie S. Prevalence of Class 1, 2, and 3 Integrons and Biofilm Formation in Pseudomonas aeruginosa and Acinetobacter baumannii among ICU and non-ICU Patients. Infect Epidemiol Med. 2016.

42. Mirahsani M, Khorshidi A, Moniri R, Gilasi HR. Prevalence of Class 1 Integron, Resistance Gene Cassettes and Antimicrobial Susceptibility Profiles among Isolates of Pseudomonas aeruginosa in Iran. Open Journal of Medical Microbiology. 2016;6(02):87.

43. Goli HR, Nahaei MR, Rezaee MA, Hasani A, Kafil HS, Aghazadeh M, et al. Prevalence and molecular characterization of Class 1 integrons among clinical isolates of Pseudomonas aeruginosa in Northwest of Iran. Molecular Genetics, Microbiology and Virology. 2017;32(2):109-15.

44. Khosravi AD, Motahar M, Montazeri EA. The frequency of class1 and 2 integrons in Pseudomonas aeruginosa strains isolated from burn patients in a burn center of Ahvaz, Iran. PloS one. 2017;12(8):e0183061.

45. Mohammadzadeh A, Mardaneh J, Ahmadi R, Adabi J. Evaluation of the virulence features and antibiotic resistance patterns of pathogenic Pseudomonas aeruginosa strains isolated from hospitalized patients in Gonabad, Iran. Archives of Pediatric Infectious Diseases. 2017;5(3).

46. Goli HR, Nahaei MR, Rezaee MA, Hasani A, Kafil HS, Aghazadeh M, et al. Role of MexAB-OprM and MexXY-OprM efflux pumps and class 1 integrons in resistance to antibiotics in burn and Intensive Care Unit isolates of Pseudomonas aeruginosa. Journal of infection and public health. 2018;11(3):364-72.

47. Pournajaf A, Razavi S, Irajian G, Ardebili A, Erfani Y, Solgi S, et al. Integron types, antimicrobial resistance genes, virulence gene profile, alginate production and biofilm formation in Iranian cystic fibrosis Pseudomonas aeruginosa isolates. Infez Med. 2018;26(3):226-36.

48. Zarei-Yazdeli M, Eslami G, Zandi H, Kiani M, Barzegar K, Alipanah H, et al. Prevalence of class 1, 2 and 3 integrons among multidrug-resistant Pseudomonas aeruginosa in Yazd, Iran. Iranian journal of microbiology. 2018;10(5):300. 
49. Salimizadeh Z, Karouei H, Masoud S, Hosseini F. Dissemination of Class 1 Integron among Different Multidrug Resistant Pseudomonas aeruginosa Strains. Medical Laboratory Journal. 2018;12(4):36-42.

\section{Tables}

Table1. Characteristics of selected studies from Iranian patients

\begin{tabular}{|c|c|c|c|c|c|c|c|}
\hline \multirow[t]{2}{*}{ Study } & \multirow[t]{2}{*}{$\begin{array}{l}\text { Publication } \\
\text { Year }\end{array}$} & \multirow[t]{2}{*}{ Location } & \multirow[t]{2}{*}{$\begin{array}{l}\text { Sample } \\
\text { Size } \\
\text { (N) }\end{array}$} & \multirow[t]{2}{*}{$\begin{array}{l}\text { MDR } \\
\mathrm{N}(\%)\end{array}$} & \multirow[t]{2}{*}{$\begin{array}{l}\text { Int1 in } \\
\text { total N } \\
\text { (\%) }\end{array}$} & \multirow[t]{2}{*}{ Units } & \multirow{2}{*}{$\begin{array}{l}\text { Correlation } \\
\text { between } \\
\text { Int1 } \\
\text { And } \\
\text { antibiotic } \\
\text { resistance }\end{array}$} \\
\hline & & & & & & & \\
\hline Yousefi[37] & 2010 & Orumieh & 160 & $21(13.1)$ & $\begin{array}{l}90 \\
(56.3)\end{array}$ & $\begin{array}{l}\text { Different } \\
\text { wards }\end{array}$ & Yes \\
\hline Moradian[25] & 2013 & Babol & 54 & $\begin{array}{l}53 \\
(98.1)\end{array}$ & $20(37)$ & ICU & Yes \\
\hline Nikokar[38] & 2013 & Guilan & 86 & $11(13.3)$ & $37(43)$ & Burn & Yes \\
\hline Moazami[39] & 2015 & Tehran & 112 & $15(13.4)$ & $\begin{array}{l}79 \\
(70.5)\end{array}$ & $\begin{array}{l}\text { Burn and } \\
\text { non-burn }\end{array}$ & Yes \\
\hline Goudarzi[40] & 2016 & Tehran & 140 & 19(13.3) & $56(40)$ & Burn & Yes \\
\hline Aryanezhad[41] & 2016 & $\begin{array}{l}\text { Bandar } \\
\text { Abbas }\end{array}$ & 90 & $12(13.3)$ & $12(13.3)$ & ICU, non-ICU & yes \\
\hline Hosseini[2] & 2016 & Tehran & 100 & - & $90(90)$ & Burn & No \\
\hline Mirahsani[42] & 2016 & Isfahan & 231 & $\begin{array}{l}192 \\
(83.1)\end{array}$ & $\begin{array}{l}146 \\
(63.2)\end{array}$ & $\begin{array}{l}\text { Burn and } \\
\text { non-burn }\end{array}$ & - \\
\hline Goli[43] & 2017 & Tabriz & 100 & 71(71) & $66(66)$ & $\begin{array}{l}\text { Burn and } \\
\text { different } \\
\text { wards }\end{array}$ & Yes \\
\hline Khosravi[44] & 2017 & Ahvaz & 93 & $93(100)$ & $\begin{array}{l}89 \\
(95.7)\end{array}$ & Burn, & - \\
\hline Mohammadzadeh[45] & 2017 & Gonabad & 95 & - & $\begin{array}{l}29 \\
(30.5)\end{array}$ & $\begin{array}{l}\text { different } \\
\text { wards }\end{array}$ & - \\
\hline Mobaraki[3] & 2018 & Tabriz & 200 & 106(53) & $\begin{array}{l}55 \\
(27.5)\end{array}$ & $\begin{array}{l}\text { Different } \\
\text { wards }\end{array}$ & Yes \\
\hline Faghri[20] & 2018 & Isfahan & 72 & - & $40(55.6)$ & ICU, non-ICU & Yes \\
\hline Goli et al[46] & 2018 & Tabriz & 57 & $57(100)$ & $57(99.1)$ & ICU & Yes \\
\hline Pournajaf[47] & 2018 & Iran & 143 & $12(8.4)$ & $27(18.9)$ & $\begin{array}{l}\text { CF } \\
\text { Patient(Iran) }\end{array}$ & - \\
\hline Zarei-Yazdeli[48] & 2018 & Yazd & 144 & 108(75) & $\begin{array}{l}119 \\
(82.6)\end{array}$ & $\begin{array}{l}\text { Burn and } \\
\text { non-burn }\end{array}$ & No \\
\hline Salimizadeh[49] & 2018 & Tehran & 21 & $21(100)$ & 19(90.5) & Different & Yes \\
\hline & & & Page 11/12 & & & & \\
\hline
\end{tabular}


Table 2. Analysis of prevalence of class 1 integron in $P$. aeruginosa recovered from clinical specimens of Iranian patients

\begin{tabular}{|c|c|c|c|c|c|c|c|c|c|}
\hline Subgroups & $\begin{array}{l}\text { Number of } \\
\text { studies }\end{array}$ & $\begin{array}{l}\text { Heterogeneity } \\
\text { test }\end{array}$ & & & $\begin{array}{l}\text { Egger's } \\
\text { test }\end{array}$ & & & $\begin{array}{l}\text { Random } \\
\text { model }\end{array}$ & \\
\hline & & $\begin{array}{l}\text { Prevalence } \\
(95 \% \mathrm{Cl})(\%)\end{array}$ & Z & $\mathrm{P}$ & $\mathrm{Q}$ & $\mathrm{P}$ & 12 & $\mathrm{~T}$ & $\mathrm{P}$ \\
\hline Int1 & 17 & $58.9(46.3-70.4)$ & 1.3 & 0.00 & 341.7 & 0.24 & 95.3 & 1.2 & 0.16 \\
\hline MDR & 14 & $55(33.8-75.3)$ & 0.48 & 0.00 & 474.1 & 0.95 & 97.2 & 0.05 & 0.62 \\
\hline
\end{tabular}

Note: Int1: Class1 Integron; MDR: Multi-Drug Resistant.

Table 3. Subgroups analysis for antibiotic resistance in $P$. aeruginosa isolated from Iranian burn patients

\begin{tabular}{|c|c|c|c|c|c|c|c|c|c|}
\hline Subgroups & $\begin{array}{l}\text { Number of } \\
\text { studies }\end{array}$ & $\begin{array}{l}\text { Heterogeneity } \\
\text { test }\end{array}$ & & & $\begin{array}{l}\text { Egger's } \\
\text { test }\end{array}$ & & $\begin{array}{l}\text { Random } \\
\text { model }\end{array}$ & & \\
\hline & & $\begin{array}{l}\text { Prevalence }(95 \% \\
\mathrm{Cl})(\%)\end{array}$ & Z & $\mathrm{P}$ & $\mathrm{Q}$ & $P$ & 12 & $\mathrm{~T}$ & $P$ \\
\hline Imipenem & 14 & $47.5(32.8-62.7)$ & 0.31 & 0.00 & 352.6 & 0.42 & 96.3 & 0.83 & 0.75 \\
\hline Ciprofloxacin & 17 & $62.4(48.6-74.5)$ & 1.7 & 0.00 & 406.7 & 0.2 & 96.06 & 1.1 & 0.07 \\
\hline Gentamicin & 15 & $60.5(47.4-72.2)$ & 1.5 & 0.11 & 288.9 & 0.37 & 95.1 & 0.9 & 0.11 \\
\hline Amikacin & 16 & $57.4(46.4-67.8)$ & 1.3 & 0.00 & 262.2 & 0.9 & 94.2 & 0.1 & 0.18 \\
\hline Ceftriaxone & 5 & $58.6(29.8-82.5)$ & 0.56 & 0.00 & 129.8 & 0.72 & 96.9 & 0.37 & 0.57 \\
\hline Ceftazidime & 14 & $57.8(44.4-70.2)$ & 1.14 & 0.00 & 289.6 & 0.99 & 95.5 & 0.00 & 0.25 \\
\hline Cefepime & 9 & $46.4(26.6-67.4)$ & 0.32 & 0.00 & 250.9 & 0.34 & 96.8 & 1 & 0.74 \\
\hline $\begin{array}{l}\text { Piperacillin/ } \\
\text { tazobactam }\end{array}$ & 10 & $50.6(40.4-60.8)$ & 0.11 & 0.00 & 102.9 & 0.35 & 91.2 & 0.97 & 0.9 \\
\hline Aztreonam & 7 & $48.1(27.9-68.9)$ & 0.17 & 0.00 & 180.7 & 0.1 & 96.6 & 1.9 & 0.86 \\
\hline Cloxacillin & 4 & 77.4(62.8-87.4) & 3.4 & 0.00 & 32.8 & 0.23 & 90.8 & 1.6 & 0.001 \\
\hline Tobramycin & 9 & $65.8(51.2-77.9)$ & 2.1 & 0.00 & 160.8 & 0.78 & 95 & 0.28 & 0.035 \\
\hline Ticarcillin & 8 & $55.4(40.1-69.7)$ & 0.68 & 0.00 & 102.5 & 0.70 & 93.1 & 0.39 & 0.49 \\
\hline Carbenicillin & 3 & 79.9(72.7-85.6) & 6.7 & 0.00 & 2.7 & 0.80 & 28.3 & 0.32 & 0.00 \\
\hline Cefotaxime & 3 & 76.6(72.1-80.6) & 9.7 & 0.00 & 9.6 & 0.96 & 79.3 & 0.05 & 0.00 \\
\hline Norfloxacin & 4 & $57.3(11.5-93.3)$ & 0.24 & 0.00 & 180.9 & 0.45 & 98.3 & 0.91 & 0.81 \\
\hline Polymyxin B & 3 & $1(1-2.5)$ & 6.4 & 0.00 & 0.001 & 0.05 & 0.00 & 121 & 0.00 \\
\hline Colistin & 3 & $1(1-1.25)$ & 4.1 & 0.00 & 0.001 & 0.06 & 0.00 & 102 & 0.00 \\
\hline
\end{tabular}

